\title{
Orações relativas do português brasileiro: estruturas cortadoras e resumptivas
}

DOI: http://dx.doi.org/10.21165/el.v50i2.2936

\section{Jaqueline Marinho Pinheiro de Almeida' \\ Heloisa Lima Salles ${ }^{2}$}

\section{Resumo}

Este estudo investiga as orações relativas cortadoras e resumptivas do português brasileiro levando em conta as análises propostas em Kenedy (2002) e Kato e Nunes (2009) e aplicando-as a dados reais de fala. A discussão aponta a análise de Kato e Nunes (2009), em que a oração relativa é formada a partir de uma estrutura de deslocamento à esquerda, como mais adequada por ser capaz de explicar as estruturas resumptivas com sintagmas nominais plenos encontradas no corpus. Indica também um caminho para o aprofundamento da investigação, dentro da Teoria Gerativa, da relativização de adjuntos com estratégia cortadora.

Palavras chave: orações relativas; gerativismo; português do Brasil.

1 Universidade de Brasília (UnB), Brasília, Distrito Federal, Brasil; jaque.letras@gmail.com; https://orcid.org/0000-0003-4219-7983

2 Universidade de Brasília (UnB), Brasília, Distrito Federal, Brasil; heloisasalles@gmail.com; https://orcid.org/0000-0002-4190-1804 


\title{
Brazilian Portuguese relative clauses: resumptive and chopping structures
}

\begin{abstract}
This article investigates chopping and resumptive relative clauses in Brazilian Portuguese, taking into consideration the analysis proposed by Kenedy (2002) and Kato and Nunes (2009) and applying them to real speech data not described in the previous analyses. The discussion points out that Kato and Nunes's (2009) analysis, in which the relative clauses are generated from a left dislocation structure, is more appropriate since it is capable of generating the structures with resumptive full DPs found in the corpus. It also indicates a way to deepen the investigation of the relativization of adjuncts with the chopping strategy within the generative framework.
\end{abstract}

Keywords: relative clauses; generative theory; Brazilian Portuguese.

\section{Introdução ${ }^{3}$}

As orações relativas não-padrão no português brasileiro têm sido objeto de vários estudos, em que se destaca a contribuição pioneira de Tarallo (1983). Neste trabalho, retomamos o tema, tendo como referência os resultados de Almeida (2011), em que dados coletados em situações reais de fala são tratados como ponto de partida da análise linguística ${ }^{4}$. A discussão está formulada no quadro teórico da gramática gerativa (CHOMSKY, 1995).

Na análise, além das relativas não-padrão descritas na literatura - as resumptivas (1) e as cortadoras (2) (TARALLO, 1983) - são encontrados dados que trazem novas perspectivas para a discussão dos estudos prévios. Entre as realizações não-padrão observadas,

\footnotetext{
3 Este trabalho desenvolve-se parcialmente, com base em dissertação de Jaqueline Marinho Pinheiro de Almeida, defendida no âmbito do Programa de Pós-Graduação em Linguística da Universidade de Brasília (2011).

4 Em resposta a um parecerista anônimo, esclarecemos que o corpus do trabalho se constitui de orações relativas não padrão, coletadas em pronunciamentos públicos de parlamentares, autoridades e cidadãos participantes de eventos públicos promovidos em instituição de caráter legislativo. Os eventos em si estão disponíveis no canal da instituição do YouTube, mas os dados desta pesquisa não se encontram em plataforma automatizada. Não houve intenção de quantificá-los, dar-lhes tratamento estatístico, caracterizar oradores, mas apenas tomá-los como base empírica para a análise. Além disso, a coleta está em andamento (assim como o estudo) e, considerando-se o fato de se tratar de fenômeno sintático, o número de ocorrências de cada tipo é reduzido. Dessa forma, não se justifica a presença de um anexo.
} 
destacam-se as orações relativas resumptivas com as seguintes características ${ }^{5}$ : (i) ocorrência de preenchimento da posição sintática relativizada por pronome demonstrativo (3) e por sintagma nominal pleno (4); (ii) ocorrência da relativa cortadora com adjuntos (em confronto com a argumentação de Kato e Nunes (2009) (5):

1. Eu fui diretora da escola que eu estudei em Ceilândia.

2. Trata-se de uma emenda dos trabalhadores da Defensoria Pública e que portanto vamos assiná-la também.

3. Só questiono uma questão técnica, que evidentemente eu não vou, com isso, colocar nenhum óbice à aprovação do projeto aqui.

4. Várias escolas públicas adotam uma carteirinha eletrônica que, ao entrar, a criança passa essa carteirinha em um leitor.

5. Foi aposta ao projeto uma emenda supressiva que nós estamos suprimindo o art. nono do projeto de lei em referência.

O artigo está estruturado como a seguir. Na sessão seguinte, apresentamos breve fundamentação do quadro teórico-metodológico tomando por base os estudos de Kenedy (2002) e de Kato e Nunes (2009) para as orações relativas e cortadoras do PB. Em seguida, passamos aplicá-las aos dados de relativas resumptivas encontrados no corpus.

5 Agradecemos a um parecerista anônimo o comentário sobre possibilidade de os dados (3) e (4) serem casos de disfluência na língua. Essa possibilidade existe. No entanto, não se trata de uma ocorrência isolada. Ainda que não numerosos (diante das restrições sintáticas envolvidas), é possível citar outro dado no mesmo corpus (ver nota 2):

(i) "Mas eu queria fazer um elogio especial ao Presidente do Iges, o Sr. Paulo, o qual nós fizemos a aprovação do seu nome para presidente" (em que o resumptivo apresenta caso genitivo, além dos traços phi).

Exemplos semelhantes também são encontrados na história do português (século XIX):

(ii) "Primeiro, qualquer Irmaõ seja quem for que por sua causa urzurpar qualquer [= qualquer irmão por cuja culpa for usurpada qualquer] alfaia da confraria <sendo justificado> fica notado por ladraõ e extinto para nunca mais servir e menos ser valido pala Caixa ou interrado (LGT em 16/12/1832. Extraído de RIBEIRO; FIGUEIREDO, 2009, apud FIGUEIREDO; SILVA, 2019, p. 300).

(iii) "[...] pois teve o atrevimento de dar uma umbigada em sua mulher, na encruzilhada do Pau-Grande, que quase a fez abortar, da qual umbigada fez cair a dita sua mulher de pernas para o ar. (Czena IX, $1^{\text {a }}$ fala do ESCRIVÃO lendo um requerimento. PENA, Martins. Juiz de paz na roça, 1883 apud FIGUEIREDO SILVA, 2019, p. 300). 
Segue-se uma discussão sobre a questão da opcionalidade de preposições nas relativas cortadoras, em confronto com a análise de Kato (2008). Conclui-se o artigo observandose que a análise de Kato e Nunes (2009) contempla as estruturas relativas resumptivas encontradas no corpus, o que permite indicar novos caminhos de investigação no âmbito da teoria.

\section{Referencial teórico-metodológico}

Conforme mencionado, a presente discussão será formulada no quadro teórico da gramática gerativa, que tem como pressuposto a hipótese de que toda língua natural consiste de um sistema finito de elementos que se combinam para formar um número infinito de sentenças. Em sua natureza complexa, recursiva e independente de estímulo, a linguagem é exclusiva e inerente à espécie humana, ou seja, todos os seres humanos e somente eles nascem com a capacidade de aprender uma língua, a Faculdade de Linguagem, desde que expostos a dados dessa língua durante os primeiros anos de vida. o processo que estabelece o desenvolvimento da gramática de uma língua específica (língua-interna) é determinado pela Gramática Universal (GU), presente como um atributo da mente/do cérebro do indivíduo.

Entre as evidências para a existência da GU apresentadas, nos estudos linguísticos, parte-se da observação de que as crianças são capazes de, a partir da exposição a um número limitado de dados linguísticos (o argumento da pobreza do estímulo), em uma faixa etária em que a cognição está pouco desenvolvida para diversas habilidades (a primeira infância), adquirir o complexo sistema de uma língua natural, por um processo semelhante em todas as culturas e com um resultado qualitativamente próximo entre os adultos.

Os linguistas de tradição gerativista têm trabalhado nas diversas estruturas das línguas do mundo para encontrar um modelo de GU suficientemente forte para explicar as questões levantadas acima e suficientemente flexível para abranger a variação entre as línguas e também a mudança linguística. A metodologia de análise linguística consiste da observação dos dados do desempenho linguístico (língua-externa) na busca de evidências que possam ser vinculadas às propriedades definidas no âmbito da Teoria dos Princípios e Parâmetros para chegar à forma da GU (CHOMSKY, 1986, 1995). Nesse modelo teórico, o conhecimento linguístico do indivíduo consiste de princípios invariantes universais e de opções de variação, os parâmetros, cujos valores são determinados no contato com os dados linguísticos primários (o input da aquisição de língua). 


\section{Estudos prévios}

\section{Kenedy (2002)}

Kenedy (2002) propõe análise das construções relativas padrão e não-padrão do português do Brasil baseada no modelo de alçamento e na hipótese de que as relativas padrão se estruturam, conforme descrito por Kayne (1994) na versão em que o item "que" é considerado como complementizador.

Na proposta do autor, as relativas resumptivas de DP do português do Brasil podem ser explicadas pela preservação, na forma fonética (Phonological Form/PF), dos traços phi após o apagamento das cópias deixadas pelo movimento do DP relativizado para a cabeça da relativa. O pronome resumptivo seria, portanto, a realização em PF desses traços phi. A derivação está ilustrada na figura 1.

Figura 1. Relativa DP resumptiva

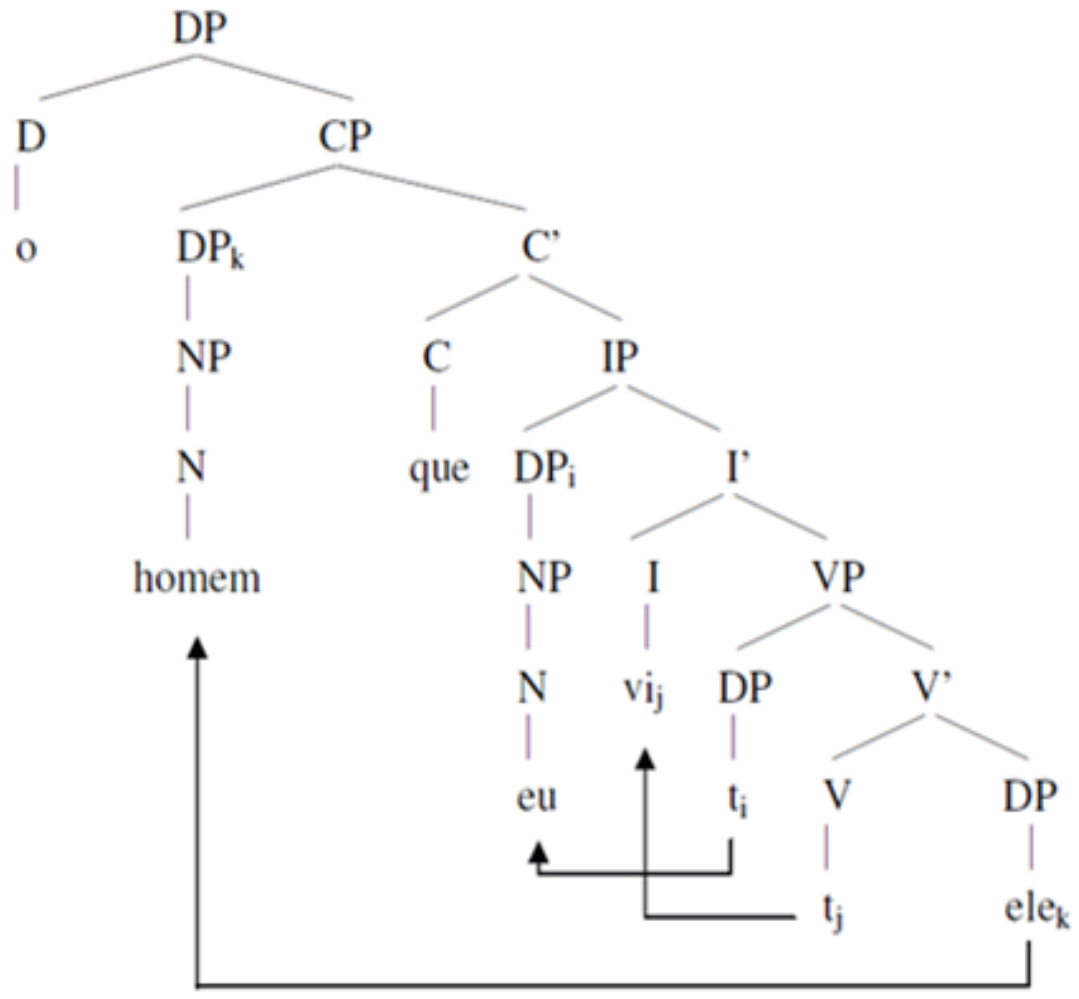

Fonte: Kenedy (2002, p. 115) 
As relativas de PP não-padrão seriam, como o fenômeno designado como preposition stranding ${ }^{6}$ de outras línguas, uma alternativa ao alto custo derivacional do pied-piping ${ }^{7}$. O autor adota, com adaptações, a análise de Salles (1997) para línguas como o PB, segundo a qual a preposição (P) e o determinante (D) formam uma composição sintática - comparável a uma preposição flexionada -, que impede a separação de P e D nas estruturas de movimento de wh/qu, com implicações para a ausência do fenômeno preposition stranding na língua em que essa composição é formada.

Kenedy propõe que existe a possibilidade do movimento do DP interno a um PP sem a preposição que o encabeça, mesmo nas línguas em que esse núcleo se forme, como alternativa à estratégia pied piping. Assim, nas relativas PP não padrão, seja a resumptiva, seja a cortadora, o DP sobre o qual recai o traço [+predicational], ou seja, o DP relativizado, se move para a cabeça da relativa sem a preposição que o encabeça. Esse movimento está ilustrado pelo movimento do DP marcado pelo índice $k$, na estrutura de cada tipo de relativa PP não-padrão explicitada a seguir.

De acordo com essa análise, na relativa PP resumptiva, assim como na relativa resumptiva de DP, ocorre o apagamento parcial da cópia do DP que ocupa a posição mais baixa da cadeia formada; os traços phi do DP (ela) são preservados, o que garante a realização da preposição (com ela), mediante a formação do núcleo [P+D]:

64 Algumas línguas permitem o movimento do DP complemento de P para fora do PP sem a preposição que o encabeça, como o inglês em The girl that I told you about $t_{i}$. Esse fenômeno é conhecido com preposition stranding (preposição órfã).

70 pied piping é o processo em que, na relativização de um DP na estrutura de um PP, a preposição é realizada como regente do pronome relativo na periferia da oração, o que configura o processo característico das relativas padrão, como em: O homem com quem ${ }_{i}$ me casei $t_{i}$. Kenedy (2007) argumenta que se trata de uma operação antinatural, para a qual as línguas apresentam estratégias de esquiva, como preposition stranding, a estratégia cortadora e o uso de resumptivos. 
Figura 2. Relativa PP resumptiva

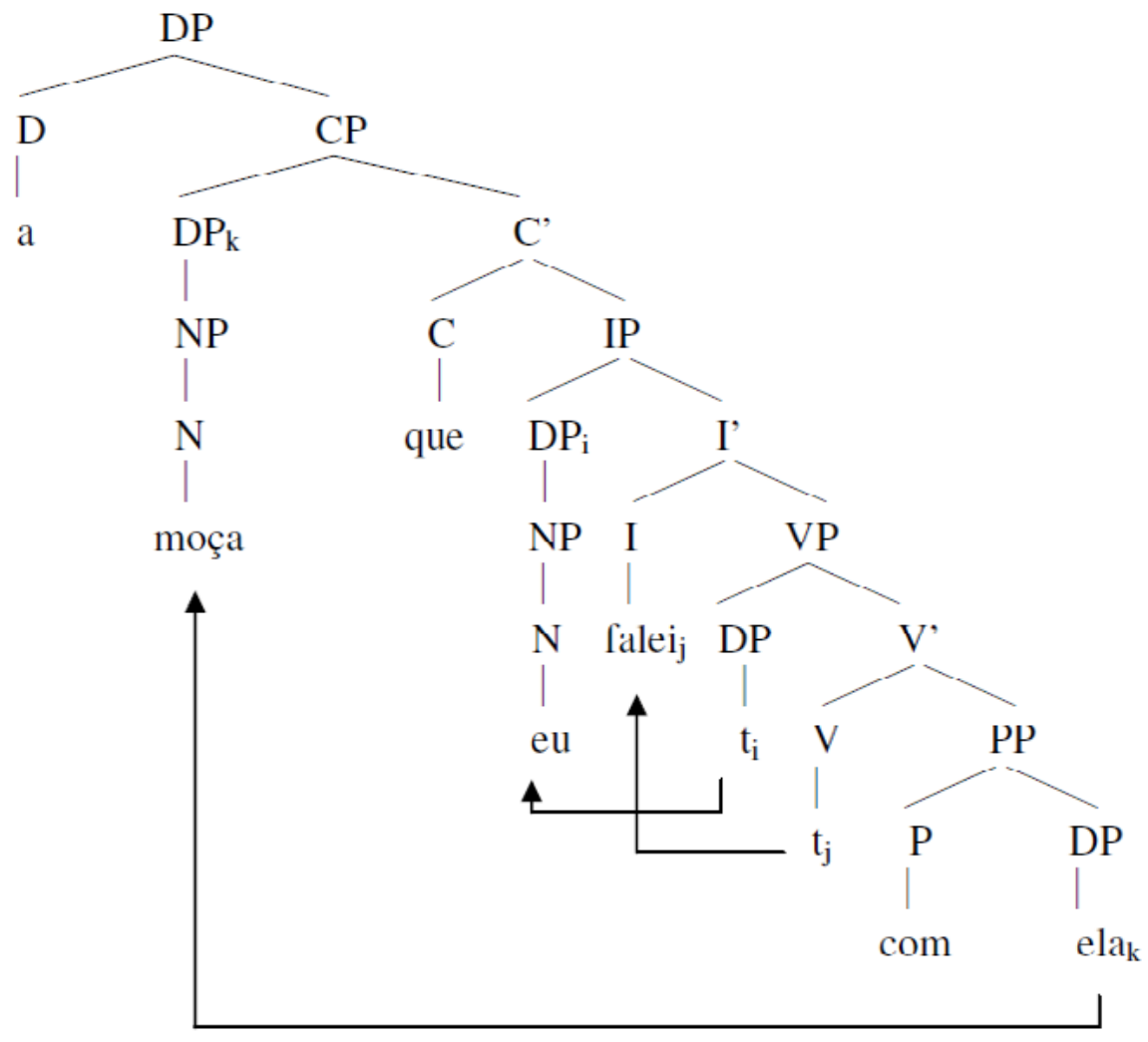

Fonte: Kenedy (2002, p. 142)

Na relativa cortadora, o apagamento da cópia do DP que ocupa a posição mais baixa da cadeia formada após o movimento de DP na relativização sem pied piping implica o apagamento da preposição que o encabeça. A estruturação de uma relativa cortadora é semelhante à de uma configuração de preposition stranding; apenas, naquele caso, o apagamento de $\mathrm{P}$ é uma exigência da redução de cadeias, pois, dada a exigência de unificação de traços na formação do núcleo $[\mathrm{P}+\mathrm{D}](\text { Agree })^{8}$, o apagamento da cópia de DP torna obrigatório o apagamento também de P em PF.

8 De acordo com Salles (1997, 1999), a formação do núcleo complexo [P+D] é determinada na sintaxe, como uma opção paramétrica, associada às línguas que não admitem preposition stranding ( ${ }^{\star}$ Quem a moça falou com?), sendo, portanto, obrigatório o carreamento da preposição (preposition pied piping) (Com quem a moça falou?). A autora acrescenta que a contração entre a preposição $(P)$ e o determinante (D) é um correlato, no nível morfofonológico, da formação de $[P+D]$ na sintaxe, o que se confirma pelo fato de ser obrigatória, no contexto de complementação entre P e D (com em "construção da/*de a casa"), enquanto é opcional, na ausência da relação de complementação (como em "existe a necessidade de as/das pessoas beberem água). Na análise de Kenedy (2002), a formação do núcleo [P+D] na sintaxe determina a ocorrência da relativa pied piping, da relativa cortadora e da relativa resumptiva (A pessoa com quem eu falei/ $A$ pessoa que falei/A pessoa que eu falei com ela), mas não da relativa com a preposição órfã ( $P$-stranding) (A pessoa que eu falei com). 
Figura 3. Relativa PP cortadora

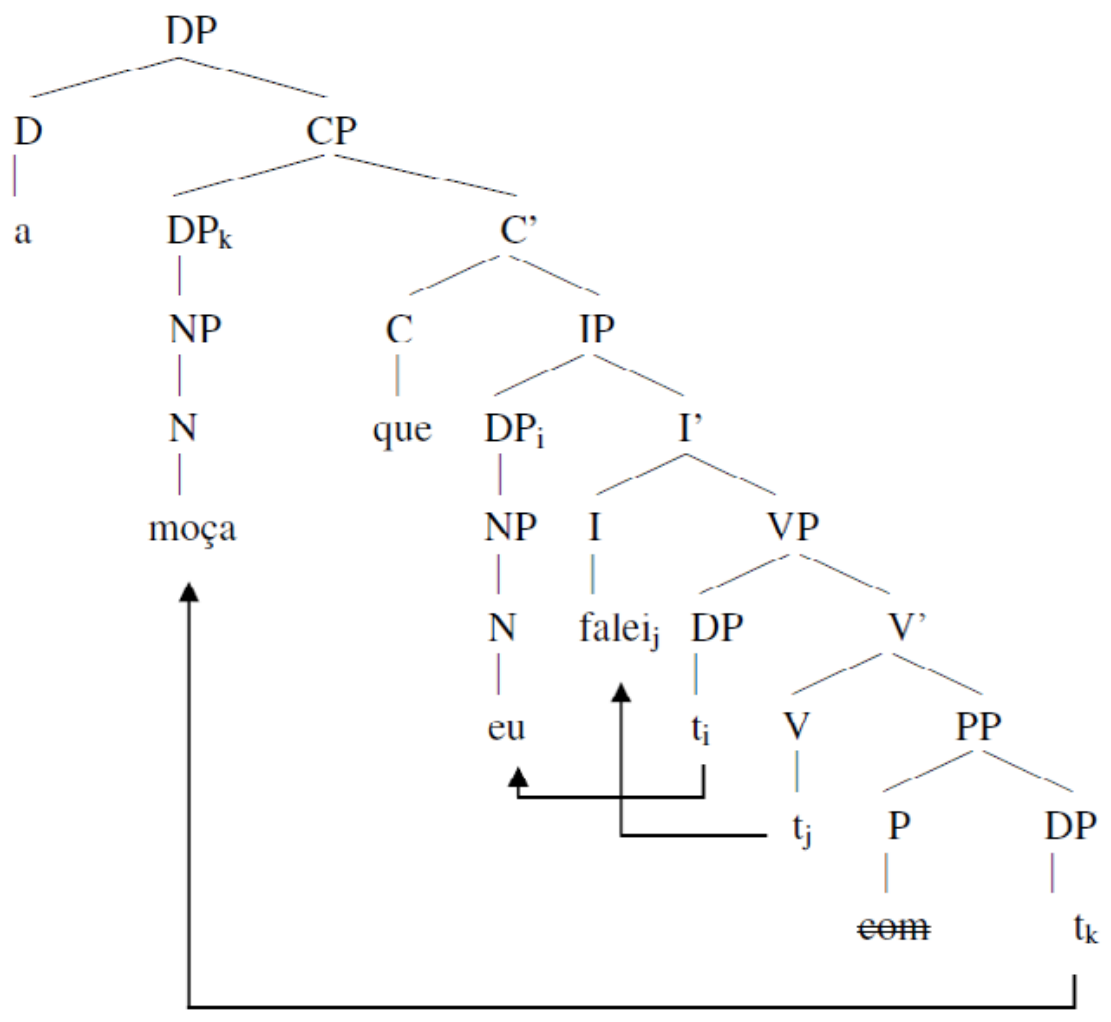

Fonte: Kenedy (2002, p. 142)

\section{Kato e Nunes (2009)}

Kato e Nunes (2009) retomam a análise de Kato (1993) das orações relativas do português brasileiro, baseada em uma adjunção da relativa ao CP da oração principal a partir de uma posição de deslocamento à esquerda na estrutura da oração relativa como origem do movimento do constituinte relativizado. Esta análise é atualizada com a aplicação da proposta de Kayne (1994), com a relativização formada por alçamento do NP relativizado, na versão em que o item que é um determinante relativo, gerado dentro do DP relativizado.

Os autores resgatam também a proposta de Tarallo (1983) de que as orações relativas padrão do PB envolvem o movimento de um pronome wh, que deixa um vestígio na posição relativizada, enquanto as relativas vernaculares são realizadas com um que complementizador e um pronome resumptivo, que pode ser nulo, no caso das relativas cortadoras (com apagamento da preposição), ou realizado foneticamente, no caso das relativas resumptivas. 
O estudo menciona a análise de Kenedy (2002) como uma opção que considera o "que" como complementizador, mas propõe que, no PB, o item que, de fato, constitui um determinante relativo com traço wh. Evidências para essa proposta são demonstradas dentro do sistema pronominal do PB, a partir da comparação com o comportamento do pronome homófono interrogativo que, da análise da inversão obrigatória do demonstrativo este na estrutura do DP antecedente (comprei um livro, livro este/*este livro que eu adoro) e das restrições à ocorrência do pronome relativo quem, este último, em termos translinguísticos, a partir do fenômeno da alternância que-qui em francês.

Segundo os autores, retomando-se a proposta de Kato (1993), tanto as relativas padrão quanto as relativas vernaculares envolvem o alçamento de um determinante com traço wh. A diferença entre as relativas vernaculares e a relativa padrão do PB seria o lugar de origem desse movimento.

Conforme demonstram as estruturas apresentadas a seguir, nas relativas padrão, o constituinte relativizado é gerado em posição argumental, dentro do IP, selecionado por um CP, que, por sua vez, ocorre como complemento de um núcleo D (cf. 6 a 8). Conforme a estrutura proposta por Kayne (1994), que é gerado como determinante do NP relativizado (que livro/de que livro), realizado na posição de sujeito, objeto direto e objeto preposicionado, em 6, 7 e 8, respectivamente, deslocando-se para uma posição em adjunção ao CP selecionado pelo núcleo D. Nessa posição, o NP é deslocado para uma posição em adjunção ao DP:9

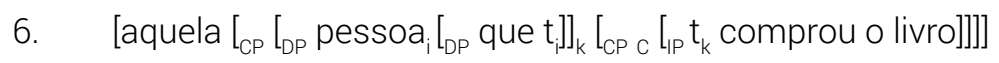

7. $\quad\left[0\left[_{C P}\left[{ }_{D P} \mid i v r o_{i}\left[{ }_{D P} \text { que } t_{j}\right]_{k}\left[\left[_{C P C}\left[l_{P}\right.\right.\right.\right.\right.\right.$ aquela pessoa comprou $\left.\left.\left.t_{k}\right]\right]\right]$

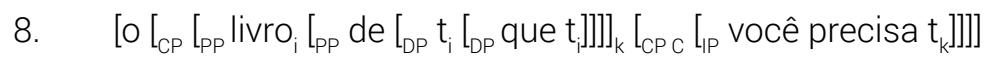

(KATO; NUNES, 2009, p. 93)

Nas relativas vernaculares, o constituinte relativizado é gerado na posição de deslocamento à esquerda interna à oração relativa, processo vinculado ao aumento da produtividade de estruturas de deslocamento à esquerda na língua, com um pronome resumptivo nulo ou foneticamente realizado na posição argumental correspondente, conforme ilustrado nos dados 9 e 10 transcritos a seguir:

9 Cabe ressaltar que, em nota, os autores afirmam que não se comprometem com a abordagem de Kayne no que diz respeito à afırmação de que a posição de Spec não é projetada, sendo os sintagmas concatenados adjungidos às projeções máximas. 
9. a. [esse livro], ele é muito bom

b. [esse livro], eu comprei ele $e_{i}$ ontem

c. [esse livro], eu estava precisando dele $e_{i}$ ontem

10. a. [esse livro], eu entrevistei a pessoa que escreveu pro ${ }_{i}$

b. [esse livro], eu falei com um aluno que estava precisando pro, ontem

(KATO; NUNES, 2009, p. 89)

Os autores apresentam ainda o seguinte contraste, que revela que nem todas as preposições podem ser substituídas por um pro juntamente com o termo regido, seja no contexto da topicalização, seja no contexto da relativização. Propõem, então, seguindo Kato (2008), que as preposições que podem ser cortadas na relativização são aquelas que atribuem caso inerente ${ }^{10}$, o que se confirma pelo fato de que são obrigatoriamente inseridas na estrutura oracional caso o NP seja pronunciado na posição interna ao VP, conforme ilustrado em 11, 12a, 13a, em oposição às estruturas de deslocamento à esquerda, conforme ilustrado em 12b e 13b.

11. Um aluno estava precisando *(d)esse livro ontem

12. a. A Maria riu *(d)o João

b. O João, a Maria riu *(dele)

13. a. Este é o livro que eu estava precisando (dele)

b. Esta é a pessoa que a Maria riu *(dela)

(KATO; NUNES, 2009, p. 90)

Os autores propõem que, na relativa cortadora, uma categoria pronominal nula pro, que faz parte do sistema de clíticos, é usada para retomar posições preposicionadas ou não, conforme ilustrado em 14 e 15 :

10 A noção de Caso inerente é definida como uma propriedade marcada no léxico, em que o DP é licenciado por preposição ou por morfologia flexional de caso, associado à interpretação de beneficiário e possuidor ou realizado como argumento de nomes e adjetivos. Distingue-se do caso estrutural, que se refere ao caso de argumentos realizados na posição de sujeito e de objeto (direto) na estrutura oracional, associados aos casos nominativo e acusativo, respectivamente (cf. CHOMSKY, 1986). 


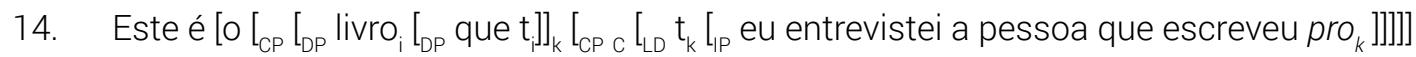

15. Este é $\left[0\left[_{C P}\left[{ }_{D P} \text { livro }{ }_{D P} \text { que } t_{j}\right]\right]_{k}\left[L_{C P C}\left[L_{L D} t_{k}\left[\right.\right.\right.\right.$ você estava precisando pro $\left.\left.\left.{ }_{k}\right]\right]\right]$

(KATO; NUNES, 2009, p. 93)

$\mathrm{Na}$ oração relativa resumptiva, um pronome resumptivo foneticamente realizado ocupa a posição dentro do IP que retoma anaforicamente o termo em posição deslocado à esquerda (Left Dislocated/LD):

16. Eu tenho [uma $\left[_{C P}\left[{ }_{D P} \text { amiga }{ }_{i}\left[_{D P} \text { que } t_{j}\right]\right]_{k}\left[_{C P C}\left[{ }_{L D} t_{k}\left[l_{P P}\right.\right.\right.\right.$ ela é muito engraçada $\left.\left.\left.\left.]\right]\right]\right]\right]$

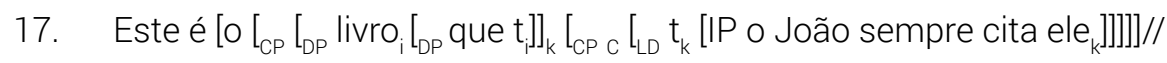

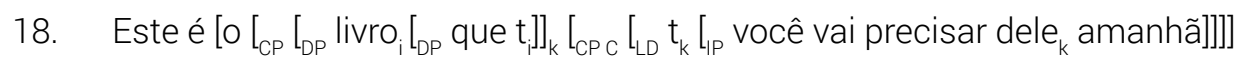

(KATO; NUNES, 2009, p. 94)

A seguir, passamos a tratar dos dados encontrados no corpus constituído para o presente estudo, que exemplificam os casos investigados nos estudos prévios e também são inovadores em relação ao que já foi descrito.

\section{Análise de dados}

Primeiramente, apresentamos, em 19, a relativa cortadora, em que a preposição que rege o pronome relativo está ausente:

19. Eu fui diretora da escola que eu estudei em Ceilândia.

A seguir, exemplificamos a relativa de PP com pronome pessoal resumptivo (em negrito):

20. Trata-se de uma emenda dos trabalhadores da Defensoria Pública e que portanto vamos assiná-la também.

Em 21, ilustramos uma relativa de PP, em que a preposição que rege o pronome relativo está ausente, e há um resumptivo realizado não por um pronome pessoal, mas pelo pronome demonstrativo "isso". 
21. Só questiono uma questão técnica, que evidentemente eu não vou, com isso, colocar nenhum óbice à aprovação do projeto aqui.

Neste ponto, retomamos a análise de Kenedy (2002), apresentada na segunda seção, para orações relativas com ausência da preposição que rege o pronome relativo, tratado como complementizador, e um pronome resumptivo na posição relativizada (relativa resumptiva de PP, cf. figura 2). Segundo o autor, os resumptivos nas orações relativas são a realização fonética dos traços phi da cópia do constituinte relativizado. Nesse caso, ao invés de ser apagada após o movimento do NP, a cópia gerada pela relativização é realizada pelos traços phi. Essa realização ocorre obrigatoriamente quando não há o apagamento da preposição que rege a cópia em línguas em que se forma o núcleo $[P+D]$, como o PB. O núcleo é formado pela concatenação da preposição com a categoria determinante, realizada por um pronome pessoal, em que estão presentes os traços phi do DP relativizado. Dessa forma, a cópia do constituinte relativizado permite que a preposição que o rege seja mantida na estrutura oracional. O pronome resumptivo seria a pronúncia em PF dessa cópia na posição de complemento do PP.

A proposta de Kenedy (2002) prevê a possibilidade de a cópia mais baixa do movimento não ser apagada. Nesse aspecto, o autor segue a proposta de Pesetsky:

Segundo Pesetsky (1998: 365), essa realização fonética múltipla ocorre também se apenas alguns traços, os traços $\varphi$ fundamentais desse constituinte, são manifestados em mais de uma posição sintática da cadeia. Ou seja, dada a cadeia $\mathrm{CH}=\left(\mathrm{a}_{\mathrm{i}}, \beta \mathrm{i}\right)$, o componente fonológico da linguagem humana poderá realizar $\beta$ de, pelo menos, três maneiras distintas: (i) $\beta$ é apagado em PF; (ii) $\beta$ é idêntico a a em PF; (iii) $\beta$ manifesta os traços $\varphi$ de a em PF. (KENEDY, 2002, p. 112).

Na análise das estruturas relativas resumptivas, o autor se detém na opção (iii), em que a cópia $\beta$ realiza os traços phi do DP movido.

Cabe notar que, em 21, o termo resumptivo é um pronome demonstrativo, realizado na posição da cópia mais baixa do movimento. Esse pronome carrega, além do traço phi de pessoa, o traço da dêixis/anáfora e o traço [-humano]. Aplicando essa análise aos dados do corpus, a estrutura seria a seguinte:

22. Só questiono $\left[_{D P}\right.$ uma $\left[_{C P}\left[_{D P} \text { questão técnica }\right]_{k}\left[C_{C^{\prime}}\right.\right.$ que $\left[_{\text {IP }}\right.$ eu não vou com isso[=questão técnica] $]_{k}$ colocar nenhum óbice à aprovação do projeto.]]]]

Essa configuração gera o questionamento quanto à possibilidade de o pronome demonstrativo "isso" ser a realização fonética dos traços phi da cópia mais baixa do 
DP "questão técnica", já que este pronome carrega mais informações do que aquelas atribuídas ao DP que participa da cadeia formada na estrutura de relativização (enquanto os traços de gênero e número estão ausentes).

Analisando o dado (23), uma hipótese seria considerar que o DP lexical "essa carteirinha" ocupa o lugar da posição sintática relativizada, o que caracterizaria uma estratégia resumptiva. Nesse caso, o DP nessa posição manifesta traços adicionais em relação ao DP relativizado "carteirinha eletrônica", tendo em vista a presença do pronome demonstrativo "essa", que manifesta o traço de dêixis:

23. Várias escolas públicas adotam uma carteirinha eletrônica que a criança passa essa carteirinha em um leitor.

Podemos aplicar a esse dado a análise proposta para as relativas resumptivas supondo que a cópia mais baixa do movimento do NP relativizado seja pronunciada, de acordo com a estrutura presente na figura 1. Nesse caso, teríamos a estrutura descrita em 24:

24. Várias escolas públicas adotam $\left[_{D P}\right.$ uma $\left[_{C P}\left[_{D P} \text { carteirinha eletrônica }\right]_{k}\left[_{C^{\prime}}\right.\right.$ que $\left[_{\mathbb{P}}\right.$ a criança passa earteirinha eletrônica] $]_{k}$ essa carteirinha ${ }_{k}$ em um leitor.]]]]

Nessa proposta, o resumptivo realiza, dentro do IP, a cópia do constituinte relativizado após o movimento. Poderíamos supor que a cópia mais baixa do movimento por algum motivo não tivesse sido apagada, mas essa suposição ainda não dá conta da diferença de realização entre o DP relativizado "carteirinha eletrônica" e aquele que de fato ocupa a posição sintática que origina o processo de relativização, "essa carteirinha". Para que essa análise fosse possível, os dois sintagmas deveriam ser idênticos, uma vez que a correspondência entre os dois é realizada por cópia de movimento.

Dessa forma, esses dados colocam um problema para a análise proposta em Kenedy (2002). Além disso, é relevante reconhecer o papel do traço associado à dêixis tanto em (23) quanto em (21).

Passamos a observar os dados sob a ótica da análise proposta em Kato e Nunes (2009), segundo a qual as relativas padrão, resumptivas e cortadoras do PB possuem um pronome relativo gerado como determinante do DP relativizado que se move para a cabeça da oração no processo de relativização. Conforme 6 a 8 e 14 a 18 demonstram, a diferença entre as estratégias padrão e vernaculares é a posição sintática de onde o constituinte relativizado é extraído nesse processo: na relativa padrão, o constituinte é gerado dentro do IP, enquanto, nas relativas vernaculares, origina-se em posição de deslocamento à esquerda na estrutura interna da oração relativa. Um pronome resumptivo correferencial 
ao constituinte relativizado é gerado dentro do IP na relativa resumptiva e substituído por um pro na relativa cortadora.

Na busca pela estrutura geradora do exemplo 21, de acordo com essa proposta, encontramos uma sentença com uma posição de deslocamento à esquerda que poderia ser o lugar de extração do constituinte relativizado: ${ }^{11}$

25. [...] questão técnica (que questiono), eu não vou, com isso, colocar nenhum óbice à aprovação do projeto.

Assumindo-se que o constituinte relativizado foi extraído da posição de deslocamento à esquerda, temos a seguinte estrutura para o dado em 21, repetido em 26a:

26. a. Só questiono uma questão técnica, que evidentemente eu não vou, com isso, colocar nenhum óbice à aprovação do projeto aqui.

b. Só questiono [uma $\left[_{C P}\left[D P \text { questão técnica }{ }_{D P P} \text { que } t_{j}\right]_{k}\left[_{C P C}\left[_{L D} t_{k} L_{I_{P}}\right.\right.\right.$ eu não vou com isso ${ }_{k}$ colocar nenhum óbice à aprovação do projeto.]]]]

Segundo essa proposta, a correspondência entre o DP relativizado [questão técnica] e o pronome resumptivo "isso" dentro do IP, se realiza por coindexação, e não cópia. Essa operação autoriza o uso do pronome demonstrativo como anafórico e com seu traço de animacidade sem as restrições enfrentadas pela operação gramatical do compartilhamento de traços phi. Portanto, essa análise não enfrenta os problemas enfrentados pela análise de Kenedy (2002).

Quando adotamos a estrutura proposta por Kato e Nunes (2009) para o dado 23, repetido em 27 , temos, novamente, a posição de deslocamento à esquerda como origem da relativização. Nesse caso, a condição para que a relativização seja possível é que a estrutura de deslocamento à esquerda seja viável na frase em questão, como em 28 :

27. Várias escolas públicas adotam uma carteirinha eletrônica que a criança passa essa carteirinha em um leitor.

28. [...] carteirinha eletrônica (que muitas escolas adotam), a criança passa essa carteirinha em um leitor.

11 Segundo a literatura (cf. AGUIAR, 2007), constituintes indefinidos não podem ser topicalizados, mas aqui, a definitude do constituinte é marcada discursivamente pela própria oração principal, o que formalizamos adicionando a oração relativa entre parênteses. 
A partir desse ponto, temos a possibilidade de relativização a partir da posição de deslocamento à esquerda, com a seguinte estrutura:

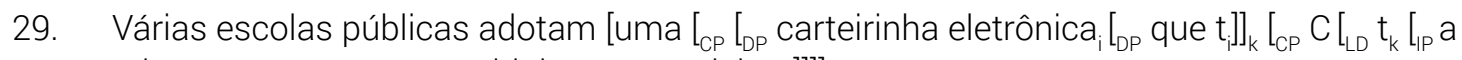
criança passa essa carteirinha ${ }_{k}$ em um leitor.]]]]

Como no exemplo anterior, o compartilhamento de traços entre o DP movido [carteirinha eletrônica] e o que ocupa sua posição correspondente dentro do IP [essa carteirinha] é feito por coindexação, e não por movimento. Nesse sentido, é possível que os dois DPs tenham a mesma referência sem que sejam idênticos em relação aos traços.

Demonstra-se assim que a análise de Kato e Nunes (2009) é capaz de gerar o tipo de relativa inovadora encontrada no corpus, aquela em que um pronome demonstrativo ou uma expressão lexical não idêntica ao antecedente da relativa ocupa, dentro do IP, a posição sintática relativizada na oração.

No que diz respeito a Kenedy (2002), os dados inovadores não convalidam a análise proposta, que precisaria de reformulações sobre as restrições de realização fonológica da cópia apagada na posição relativizada interna ao IP para aplicar-se aos dados trazidos por este trabalho.

Por isso, apontamos a estrutura proposta por Kato e Nunes (2009) como mais adequada para abranger a extensão da variação encontrada nas orações relativas do PB. Os dados coletados e apresentados nesta seção, juntamente com sua análise, trazem, portanto, como contribuição para a discussão sobre as relativas vernaculares do PB, evidência adicional não contemplada pelos autores de que as configurações de orações relativas resumptivas podem ser geradas a partir de uma posição de tópico interna à oração relativa, com a qual a posição interna ao IP se identifica por coindexação, sem as restrições exigidas pela realização da cópia.

\section{Sobre a relativização de adjuntos em estruturas cortadoras}

Nesta seção, examinamos a relativização de adjuntos em relativas cortadoras, considerando alguns dados encontrados no corpus, que apontam para a necessidade de discutir o contraste entre a relativização de posições argumentais preposicionadas e a relativização de adjuntos. Observamos que, nos casos de relativização de posições argumentais preposicionadas, ambas as análises citadas anteriormente seriam satisfatórias para explicá-los. No entanto, alguns dados podem contribuir para a discussão sobre o estatuto gramatical da preposição em diversos contextos sintáticos, na relação com o contexto da estratégia cortadora de relativização no PB. 
Kenedy (2002) não apresenta contraste entre preposições que podem e não ser apagadas na relativa cortadora. O contraste de gramaticalidade proposto por Kato e Nunes (2009) em 13 e retomado em 30 revela que há distinções entre as preposições com relação à possibilidade de apagamento na relativa cortadora.

30. a. Este é o livro que eu estava precisando (dele)

b. Esta é a pessoa que a Maria riu *(dela)

(KATO; NUNES, 2009, p. 90)

Conforme mencionado, os autores atribuem o contraste ao tipo de caso licenciado pela preposição. Poderiam ser cortadas apenas as preposições licenciadoras de caso inerente, aquele atribuído a constituintes selecionados pelo verbo ou nome em relação próxima com seu complemento (CHOMSKY, 1986).

Esse contraste é originalmente apresentado em Kato (2008), que investiga vários contextos sintáticos de opcionalidade de preposições e conclui que as preposições lexicais, que introduzem adjuntos, não seriam opcionais e, consequentemente, as relativas cortadoras de constituintes desse tipo seriam agramaticais.

Em contraponto, nossa pesquisa encontrou uma série de dados de relativas cortadoras de constituintes em contexto de adjunção. Em alguns casos, é difícil recuperar exatamente a preposição que foi apagada, mas isso não impede a realização das sentenças e, por conseguinte, o reconhecimento de sua ocorrência na gramática do PB.

31. E com isso nós tivemos que entrar na Justiça, enfim, entrar com um processo bastante longo e que a gente fica se perguntando: a gente tem que se defender de pessoas que querem fechar uma escola?

32. Foi o único órgão que deu esse atendimento, que acolheu e que hoje os pais sabem se a pessoa possui esse distúrbio ou não.

33. Mas os pais também estão mal-educados, até pelas centenas de dias que eles vêm aqui deixar os seus filhos e não tem vagas.

34. Foi aposta ao projeto uma emenda supressiva que nós estamos suprimindo o art. nono do projeto de lei em referência. 
Em 31 e 32, podem estar em jogo truncamentos sintáticos próprios da fala espontânea. Entretanto, em 33 e 34, percebe-se claramente que o constituinte relativizado sem a preposição que rege o pronome relativo está em contexto de adjunção, e a preposição ausente (supostamente cortada) tem estatuto de categoria lexical, que institui uma relação argumental com DP que seleciona, não sendo, portanto, uma categoria que apenas licencia um Caso atribuído pelo verbo aos argumentos por ele selecionados.

Nesse sentido, um caminho que pode lançar luz sobre a discussão da estrutura das orações relativas cortadoras do PB é a investigação do contraste entre o tipo de função que pode ser relativizada, em relação a questões como caso inerente e caso estrutural. Tais questões permitem aprofundar o estudo da relativização de posições de adjunção. Em particular, conforme observado em Almeida (2011), é possível que, em alguns casos de relativas cortadoras, o pronome relativo que retoma adjuntos adverbiais esteja associado às estruturas com o chamado "advérbio nu", um contexto em que o adjunto é realizado por um DP (locativo temporal) ${ }^{12}$, sem a necessidade de uma preposição foneticamente realizada (cf. LARSON, 1985), como o DP "centenas de dias", em 33. Deixamos a investigação dessa hipótese e de outras questões correlatas para pesquisa futura.

\section{Considerações finais}

Buscamos, neste trabalho, avaliar duas propostas para as orações relativas não-padrão do português brasileiro e aplicá-las a dados reais de fala coletados em pronunciamentos públicos em instituição parlamentar.

Para tanto, consideramos inicialmente a proposta de Kenedy (2002), demonstrando que é compatível com as estruturas que apresentam pronome pessoal resumptivo, mas encontra incompatibilidade quando aplicada a dados do corpus, em que pronomes demonstrativos e expressões lexicais resumptivas ocorrem na posição sintática relativizada. Em particular, a análise enfrenta problemas relacionados às restrições impostas pela suposição de que o resumptivo da oração relativa é resultado da realização fonológica parcial da cópia do constituinte relativizado (os traços phi), uma operação realizada no nível de PF e sujeita a condições específicas (supostamente que tais traços estejam contidos nos traços formadores desse DP).

Os mesmos dados encontraram possibilidade de análise na estrutura proposta por Kato e Nunes (2009), que, por considerar que a identificação entre o resumptivo e constituinte relativizado se dá por coindexação, e não por cópia, admite as formas de realização fonológica do resumptivo encontradas no corpus - particularmente que haja traços gramaticais/categorias não disponíveis na estrutura do DP relativizado.

12 Essa questão será abordada com mais detalhes na continuidade do trabalho, que se encontra em desenvolvimento. 
A contribuição deste estudo consiste portanto na apresentação de evidência adicional para a proposta de Kato e Nunes (2009), pela verificação da possibilidade de aplicar a proposta baseada na posição de deslocamento à esquerda como lugar de origem da relativização em orações relativas resumptivas do PB.

Em relação às relativas cortadoras, os dados do corpus apontam para a necessidade de seguimento na investigação sobre o tipo de preposição que pode ser cortada nessas configurações no que diz respeito aos contrastes apresentados em Kato e Nunes (2009) e Kato (2008), uma vez que foram identificados casos de apagamento da preposição que não se coadunam com a tipologia proposta pelos autores.

\section{REFERÊNCIAS}

AGUIAR, A. C. Da estrutura de Expressões Quantificadas em Posição de Tópico. 2007. Dissertação (Mestrado em Linguística) - Instituto de Letras, Universidade de Brasília, Brasília, 2007. Disponível em: https://repositorio.unb.br/handle/10482/1107. Acesso em: 30 set. 2020.

ALMEIDA, J. M. P.; SALLES, H. M. L. Análise das Estruturas Relativas do Português do Brasil. Anais do VII Congresso Internacional da ABRALIN, Curitiba, p. 1965-1978, 2011.

ALMEIDA, J. M. Estruturas de Relativização do Português do Brasil. 2011. Dissertação (Mestrado em Linguística) - Instituto de Letras, Universidade de Brasília, Brasília, 2011. Disponível em: https://repositorio.unb.br/handle/10482/9240. Acesso em: 30 set. 2020.

CORRÊA, V. Orações relativas: o que se sabe e o que se aprende no português do Brasil. 1998. Tese (Doutorado em Linguística) - Instituto de Estudos da Linguagem, Universidade Estadual de Campinas, Campinas, 1998. Disponível em: http://repositorio. unicamp.br/bitstream/REPOSIP/269159/1/Correa_VilmaReche_D.pdf Acesso em: 30 set. 2020.

CHOMSKY, N. Knowledge of Language. Its Nature, Origin and Use. Westport / London: Praeger, 1986.

CHOMSKY, N. The Minimalist Program. Cambridge, Mass.: MIT Press, 1995. cap. 4.

FIGUEIREDO E SILVA, M. C. "Uma história das relativas do português brasileiro." In: GALVES, C.; KATO, M.; ROBERTS, I. Português brasileiro. Uma segunda viagem diacrônica. Campinas: Editora da UNICAMP, 2019. p. 283-312. 
KATO, M. Recontando a História das Relativas em uma Perspectiva Paramétrica. In: KATO, M. Português Brasileiro: uma viagem diacrônica. Campinas: UNICAMP, 1993.

KATO, M. Optional Prepositions in Brazilian Portuguese. Poster presented at the 38th Linguistic Symposium on Romance Languages (LSRL), University of Illinois at UrbanaChampaign, 4-6/4/08, 2008. Disponível em: http://linguistica.fflch.usp.br/sites/ linguistica.fflch.usp.br/files/inline-files/28_1.pdf. Acesso em: 30 set. 2020.

KATO, M.; NUNES J. A Uniform Raising Analysis for Standard and Nonstandard Relative Clauses in Brazilian Portuguese. In: NUNES, J. Minimalist Essays on Brazilian Portuguese Syntax. . Amsterdam: John Benjamins, 2009. p. 93-120. Disponível em: https://www. researchgate.net/publication/300845953_A_Uniform_raising_analysis_for_standard_ and_nonstandard_relative_clauses_in_Brazilian_Portuguese. Acesso em: 30 set. 2020.

KAYNE, R. The Antisymmetry of Syntax (Linguistic Inquiry Monographs, 25). Cambridge, MA: MIT Press, 1994.

KENEDY, E. Aspectos estruturais da relativização em português: uma análise baseada no modelo raising. 2002. Dissertação (Mestrado em Linguística) - Instituto de Letras, Universidade Federal do Rio de Janeiro, Rio de Janeiro, 2002. Disponível em: https:// www.gepex.org/eduardo/artigos_arquivos/dissertacao_eduardokenedy_2003.pdf. Acesso em: 30 set. 2020.

KENEDY, E. A antinaturalidade de pied-piping em orações relativas. 2007. Tese (Doutorado em Linguística) - Faculdade de Letras, Universidade Federal do Rio de Janeiro, Rio de Janeiro, 2007.

LARSON, R. K. Bare-NP adverbs. Linguistic Inquiry, v. 16, p. 595-621, 1985.

SALLES, H. M. Prepositions and the Syntax of Complementation (Doctoral Dissertation). Bangor: University of Wales, 1997.

TARALLO, F. Relativization Strategies in Brazilian Portuguese. Ph.D. dissertation. University of Pennsylvania, 1983. 